BAPL, 37. 2003 (107-114)

\title{
BREVE ITINERARIO POR LA POESÍA PERUANA CONTEMPORÁNEA
}

\section{Luis Fernando Jara}

Es sabido que la poesía norteamericana contemporánea se erigió a partir de dos padres fundadores, dos paradigmas casi inexorables para quienes se animaron a ejercer el recurrente oficio de trabajar la palabra: Walt Whitman, de un lado, con una poética exultante, vitalista y coral, y, en la otra ribera, con una voz más queda, apagada e intimista la difuminada y sutil imagen de Emily Dickinson. Un fenómeno relativamente parecido ocurre en la poesía peruana. Hay también dos voces, las de Eguren y Vallejo -aunque no tan disímiles como las de los poetas norteamericanos- las que constituyen los ejes fundacionales de nuestra poesía. .

José María Eguren (1874-1942) es, qué duda cabe, el primer poeta moderno del Perú -en el sentido de renovador, de fundador-, el solitario representante y heredero del simbolismo que asomara su rostro, para decir sutiles verdades, pintarnos extraños paisajes y dibujarnos fantásticos personajes en un timbre distinto de aquel que insistentemente repetían los poco afortunados herederos del modernismo. En 1911, cuando publica Simbólicas, la poesía peruana cambió de rumbo, alteró sus mapas y dispuso su proa para encaminarse en otra dirección. Su atmósfera sutil, sus personajes entrevistos desde 
el intersticio entre la vigilia y el sueño, su lenguaje pulcro, delicado y bello -en el más estricto sentido de la palabramarcaron otra pauta, dijeron con otro lenguaje.

Poco tiempo después aparece César Vallejo (1892-1938). $\mathrm{Su}$ entrada en la poesía peruana no fue precisamente perturbadora ni triunfal. En 1918, publica Los Heraldos Negros, libro desigual, con clara filiación modernista. Aunque se advierte ya la genialidad que concentrará en su libro siguiente, LHN dista mucho de ser un libro revelador. Trilce, publicado en 1922, si lo es de pies a cabeza. Libro revelador, abrumador, contundente, vanguardista por derecho propio, revolucionario por actitud y por prédica, Trilce fue una irrupción, una cachetada en los castos oídos todavía modernistas de la poesía peruana (recuérdese que en 1924, cuando Vallejo ya había abandonado el país, Chocano fue proclamado Poeta Nacional por el dictador Leguía, lo que implica la vigencia que entonces tenían los cultores del cisne). En 1923, Vallejo viaja a Francia de donde nunca regresará. Poco tiempo después de su muerte aparecen póstumamente dos extraordinarios libros: Poemas Humanos y España, aparta de mi este cáliz.

Trilce, entonces, consolida y asegura el cambio que había iniciado el silencioso Eguren. Cinco años después, verá la luz uno de los libros más singulares de la poesía peruana: Cinco metros de poemas. Un libro objeto, una película para ser vista, un acordeón para desplegarse con sutil armonía, una fruta para ser pelada, una pequeña cajita musical, el diario de un pasajero que lee la ciudad y, además, una deliciosa burla del capitalismo, con esa atroz vocación deshumanizadora, que todo lo valora como una mercancía: todo esto nos heredó Carlos Oquendo de Amat (1905-1936), síntesis exacta de todas las vanguardias que se asomaban entonces. El cine, la gran novedad y la gran apuesta estética de los años veinte, fue el espejo y el mejor pretexto para la ideación y escritura de estre breve y bello libro. Esta apuesta por el cine como elemento motivador lo veremos también en Cinema de los sentidos puros, libro de Enrique Pena Barrenechea publicado en 1931. 
La década del 30 nos sorprenderá con dos extraordinarios poetas: Emilio Adolfo Westphalen (1911) -recientemente fallecido- y César Moro (1903-1956). Westphalen publicó dos breves libros -Las insulas extrañas y Abolición de la muerte, 1933 y 1935, respectivamente- y guardó silencio por casi cuarenta años. Durante ese largo camino de negación de la voz, la sabiduría poética de EAW poco a poco se hizo sentir. Estos dos libros son el ejemplo contundente de un surrealismo bien asimilado, sin espavientos ni imposturas, y guiado por una mano que demostró una maestría impecable para dejarnos poemas de una abrumadora perfección formal. Sus libros posteriores Belleza de una espada clavada en la lengua, Ha vuelto la diosa ambarina, etc., han confirmado tamaña calidad.

César Moro fue, cabalmente, el único auténtico surrealista de la poesía hispanoamericana al conciliar en una unidad indisoluble vida y poesía. Fulminó la frontera social entre el poeta y el ciudadano e hizo de su vida una alquimia perfecta entre la libertad, el amor y el malhadado oficio de escritor.

Disidente de sí mismo, de su patria y de su lengua -recuérdese que su nombre verdadero fue Alfredo Quispez Asín, que vivió buena parte de su vida entre Francia y México y que el grueso de su producción poética está escrita en francés-, Moro nos ha dejado una escritura incandescente, visceral y perturbadora. La tortuga ecuestre y Lettre d'amour son titulos absolutamente imprescindibles en la poesía peruana.

A fines de los treinta y comienzos de los cuarenta, se deja sentir una de las voces más extrañas y extraordinarias de nuestra poesía: la de Martín Adán (1908-1985). Su nombre no era una novedad, pues en 1928 había publicado un precoz y fabuloso libro, La Casa de Cartón, la primera novela vanguardista de nuestra literatura. Sin embargo, es en 1939, cuando publica La rosa de la espinela, que Martín Adán inicia un deslumbrante y prolífico camino por el que transitarán muchos poetas posteriores. Adán ha pasado desde la experimentación 
vanguardista visible en su primer libro y primeros poemas hasta la revigencia de las formas tradicionales, pasando por el virtuosismo formal y el hermetismo metafísico. Travesía de extramares, Escrito a ciegas, La mano desasida y La piedra absoluta son libros de consulta obligada para quien quiera asomarse con lúcida curiosidad a la poesía peruana.

A mediados de la década del cuarenta y hasta bien entrada la del cincuenta se acentúa en nuestra poesía una doble tendencia que devendrá en dos frentes, dos estilos, dos formas de asumir y hacer la poesía: la poesía social -encarnada por Valcárcel, Romualdo- y la poesía pura -encarnada por Sologuren, Eielson y Varela-. Esta oposición se verá cuestionada por poetas que tenían una mirada crítica sobre el contexto social de entonces y lo proclamaban con un esmero formal y un oficio impecables. A esta lista pertenecen poetas como Wáshington Delgado, Carlos Germán Belli y Juan Gonzalo Rose.

Sologuren (1911) ha ido configurando su obra a partir de un solo libro: Vida Continua, una lectura de las contradicciones que asolan al hombre -eros y tánatos, deseo y realidad, vida y muerte- escrito con pulcritud, a veces un tanto hermético, a veces de una limpidez conmovedora.

El caso de Eielson (1924) es excepcional. Se ha desplazado en distintos terrenos de las artes plásticas y la literatura con una solvencia abrumadora. Su poesía es la mejor conjunción de ese extraordinario talento. Desde Canción y muerte de Rolando y Reinos hasta Papel, su poesía es una arriesgada aventura formal que va desde una prosa virtuosa y trabajada con maestría -pese a sus escasos 20 años- hasta los experimentos más inverosímiles que dan cuenta de un paulatino desencuentro -o desencanto- de la palabra y una cercanía cada vez más cómoda a la imagen. Libros como Habitación en Roma y Mutandis son referentes ineludibles en nuestra poesía.

Blanca Varela (1926) es la voz femenina más importante de la poesía peruana. Su lenguaje, con iniciales reminiscencias 
surrealistas, es rico en recursos e imágenes. Su producción es relativamente breve, pero se compensa largamente con la vasta variedad temática y formal. Cada poema es un rostro distinto, una voz novedosa lista para sorprender al lector. Canto Villano y Concierto animal son sus libros más significativos.

Wáshington Delgado (1927) es uno de los pocos peruanos que por la calidad y contundencia de su obra merecen un lugar más privilegiado del que gozan ahora. Su obra inicial ejemplifica la impronta de la poesía de la generación del 27, pero que luego fue tomando cuerpo hasta constituir una voz más sólida y más auténtica. Las resonancias sociales y políticas se dejan oír con natural claridad bajo el entramado de un lenguaje rico en formas, matices y ritmos. Como él mismo lo ha proclamado en el prólogo a su Reunión elegida, a lo largo de su trayectoria poética ha buscado explorar diversas formas expresivas, de tal modo que ha pasado desde el poema y verso breve hasta el poema en prosa.

La década del sesenta fue una especialmente rica y variopinta: tres poetas importantes hicieron su aparición en el espectro de la poesía peruana. Javier Heraud. (1942-1963) había ganado los más importantes premios de poesía y había publicado sus dos importantes libros -El Río y El Viajeantes de cumplir los veinte años. Luego de una precoz y exitosa trayectoria, decidió viajar a Cuba lo que cambió radicalmente su vida, pues llegó en momentos en que la revolución vivía la apoteosis del triunfo y validación frente a todo el 'mundo. Él sintonizó rápidamente con los preceptos marxistas y esto lo trajo al Perú, pues había la intención de extender la revolución a estos lares. A los veintiún años murió acribillado en Puerto Maldonado. Con él murió lo que hasta ese momento era considerado el más importante proyecto poético de la literatura peruana. Con él murió también la voz vitalista que le cantaba a la naturaleza y al pueblo.

Luis Hernández (1941-1977) es un caso excepcional en nuestra poesía. Al igual que Moro y Eielson, su poesía tiene 
estrechos e íntimos contactos con las artes plásticas. Sorprende, además, su extraña concepción de la poesía. Luego de publicar un brevísimo conjunto de poemas -Orilla, bajo el auspicio de Javier Sologuren-renuncia a la publicación y se dedica a llenar decenas de cuadernos -que regalaba a sus amigos- con bellos dibujos y sorprendentes poemas escritos-dibujados con una hermosa caligrafía. La oralidad, el coloquialismo, la ciudad y sus viandantes, la ironía, la música, la intromisión de vocablos en distintas lenguas, la sutil y tierna irreverencia son los rasgos que mejor definen sus poemas. Gracias al esfuerzo invalorable de sus amigos -Yerovi, La Hoz- y de otros estudiosos se ha logrado reunir una muestra significativa de esos libros y tener una idea más cabal de su talento, de su delicioso humor.

Antonio Cisneros (1942) es uno de los poetas más conocidos e influyentes de la poesía peruana. Con Rodolfo Hinostroza constituyen la clara evidencia de la importancia que tuvo en esta generación la lectura de los poetas en lengua inglesa -las referencias a Eliot y Pound son inevitables-, a diferencia de sus predecesores que se interesaron por poéticas en otras lenguas. A esto incorpora una inteligente lectura de la tradición poética a la que constantemente reescribe. A esto incorpora una inteligente lectura de la tradición poética a la que constantemente reescribe. Cisneros ha demostrado una versatilidad poco común para mudar de temas y recursos, pero siempre subyace - tras la ironía, a veces desenfadadauna mirada crítica, lúcida sobre nuestro tiempo, sobre nuestro espacio. A través de su lenguaje se alza una voz que indaga, celebra, desnuda, acoge e intima felizmente con el lector. Entre sus muchos libros publicados figuran Comentarios reales (1964), Canto ceremonial contra un oso hormiguero (1968), Como higuera en un campo de golf (1972), El libro de Dios y de los húngaros (1978) y Crónica del Niño Jesús de Chilca (1981). Ha obtenido muchos premios nacionales e internacionales. El último ha sido el Premio de Poesía Gabriela Mistral.

Los poetas de la década del setenta irrumpirán en la poesía peruana con una voz imprecadora: cuestionarán su 
tradición inmediata, cerrarán los libros y abrirán los ojos y las manos para ver y tomar lo que las calles les proponían. De allí sale la poesía inmedialista, de aliento popular y coloquial que darán a publicar. Hora Zero será el grupo que convoque a los más representativos poetas de esta generación, entre los que destaca largamente la obra de Enrique Verástegui (1950), el más osado y virtuoso de ese grupo. Sin embargo, la década del 70 nos sorprenderá aún más con otro poeta -José Watanabe (1946) - singular, extraordinario, que trabajaba una poesía a contrapelo de lo que hacían en ese momento sus pares.

Watanabe es uno de los más importantes poetas peruanos e hispanoamericanos de los últimos tiempos. Cuando sus pares setenteros le sacaban la lengua a la tradición -Verástegui llega a firmar que no le interesaba Vallejo y que, además, había perdido vigencia e intensidad-y practicaban un lenguaje demasiado emparentado con la oralidad, Watanabe nutre su voz no sólo del aliento de nuestra tradición, sino que apela, además, a aquella remota y rica tradición japonesa que le es natural por su filiación oriental. En sus poemas, de un virtuosismo poco visto en los últimos tiempos, se sintetizan felizmente las experiencias que le prodiga su entorno laredino y la continencia, mesura, exactitud aprendida de los viejos cultores del haiku, a los que se aproximó gracias a la paciente lectura de su padre. Nada afecto a las publicaciones ni a las fiestas celebratorias que estas implican -la sencillez y la sobriedad lo definen enteramente- tiene hasta ahora solo cuatro libros publicados: Álbum de familia, El huso de la palabra -considerado por la crítica como el mejor libro de la década del 80-, Historia Natural y Cosas del cuerpo. Recientemente se le ha publicado una antología de sus poemas bajo el titulo de El Guardián del hielo.

Los poetas de la década del 80 desandarán' el camino trajinado por sus predecesores y se abocarán a la aventura creadora de construir una poética más personal tomando como referentes a los poetas del 60 y de la década del 40 . En estos apuros encontramos a dos notables voces: Eduardo Chirinos 
(1960) y José Antonio Mazzotti (1961). Difícilmente se puede hallar una antología reciente de la poesía hispanoamericana en la que no aparezca incluido Chirinos. Desde la aparición de su primer libro Cuadernos de Horacio Morell (1978) hasta el último publicado Abecedario del agua (2000) su poética ha confluido en la conformación de un lenguaje riguroso que trasunta el sistemático y dedicado ejercicio de la palabra y una lectura atenta y lúcida de su tradición.

José Antonio Mazzotti fue celebrado desde la aparición de sus primeros poemas. Se le reconoció un lenguaje limpio, suelto, flexible con profundas raíces en la tradición occidental y un disciplinado conocimiento de la tradición poética peruana. En 1999 salió publicado El Zorro y la luna, antología que recoge sus poemas mejores.

La década del noventa aparecerá con jóvenes que acentuarán la búsqueda personal iniciada por sus inmediatos predecesores. Los lenguajes y las temáticas han sido disimiles, una previsible respuesta a los tiempos. Aunque podría parecer todavía prematuro hacer un balance o señalar nombres significativos, diversas antologías y textos críticos han centrado su atención en cuatro o cinco nombres que seguramente consolidaran sus propuestas en los próximos tiempos: Alonso Rabí (1964) con tres libros publicados -Concierto en el subterráneo, Quieto vaho sobre el espejo y En un purísimo ramaje de vacíos-, Xavier Echarri (1966) con su excepcional Las quebradas experiencias, Luis Fernando Jara (1969) que publicó Zona Dark en 1991 y Lorenzo Helguero (1969) con cinco libros: Sapiente lenguae, Boletos, Diario de Darío, Beissan o el abismo y El amor en los tiempos del cole. 